\title{
СРАВНИТЕЛЬНЫЙ АНАЛИЗ ФАКТОРОВ И СТИМУЛОВ ПЕРЕРАБОТКИ ОТХОДОВ: МЕЖДУНАРОДНЫЙ ОПЫТ
}

\section{(c) 2019 Никифорова Наталья Александровна}

кандидат экономических наук, доцент, профессор Департамента учета, анализа и аудита Финансовый университет при Правительстве Российской Федерации

125993, г. Москва, Ленинградский пр-т, д. 49

E-mail: nanikiforova@fa.ru

\section{(c) 2019 Миловидова Светлана Николаевна}

кандидат экономических наук, доцент, доцент Департамента учета, анализа и аудита Финансовый университет при Правительстве Российской Федерации

125993, г. Москва, Ленинградский пр-т, д.49

E-mail: snmilovidova@fa.ru

Увеличение масштабов переработки отходов является одной из целей политики во многих странах. Переработка бытовых отходов, в большей степени основана на добровольных усилиях. Поэтому интересно понять механизмы, стоящие за добровольными решениями переработки бытовых отходов и их влияние на различные стратегические меры. В статье описываются различия в факторах, влияющих на деятельность по переработке бытовых отходов. По 10 странам проанализированы наиболее важные мотивы для переработки бытовых отходов. Увеличение предоставление услуг по переработке бытовых отходов оказывает значительное влияние на сбор и переработку отходов домашних хозяйств наиболее эффективными методами. Кроме того, результаты показывают, что разработка денежных стимулов может иметь важное значение, чтобы избежать вытеснения морально мотивированных добровольных сборов, о чем свидетельствует успех Кореи.

Ключевые слова: сравнительный анализ, переработка бытовых отходов, международное сравнение, утилизация, рециркуляционная деятельность.

Образование отходов и истощение ресурсов вызывают серьезную озабоченность во многих странах, поэтому сбор и переработка бытовых отходов домашних хозяйств рассматриваются в качестве средств уменьшения этих проблем. Утилизации бытовых отходов происходит в значительной степени за счет добровольных мотивов отдельных домохозяйств. Некоторые страны используют меры и нормативные акты, стимулирующие эти усилия, в других странах стимулов практически не существует. Власти многих стран предоставляют для сбора и переработки отходов только оборудование (ящики, контейнеры и др.). Несмотря на это, домохозяйства прилагают значительные усилия: сортируют, складывают, моют, грузят и транспортируют сортированные отходы, даже когда нет экономических стимулов. Это означает, что экономические мотивы имеют важное значение для деятельности по переработке бытовых отходов домашних хозяйств. Важно отметить, что внутренние мотивации, введение экономических стимулов или других правил могут существенно повлиять на то, как домохозяйствам нужно предоставлять услуги по утилизации отходов. Для достижения властями своей цели увеличения числа домашних хозяйств, участвующих в сборе и переработке отходов, а также обеспечения разработки наиболее эффективных инструментов муниципальной политики имеют большое значение [1]. Это необходимо для того, чтобы понять механизмы добровольного участия в переработке бытовых отходов и то, как это влияет на введение экономических стимулов.

Как нормы и стимулы влияют на утилизацию?

То, как мы живем, влияет на то, как мы себя чувствуем. Последствия несоблюдения норм утилизации отходов, в конце концов, скажутся на нашем благополучии и, следовательно, на нашем поведении. На рисунке 1 показан основной механизм модели влияние на полезность переработки бытовых отходов в Халворсене, предложенный в 2008 году [2].

Наши действия, в данном случае бытовая переработка (первая контур), как предполагает- 


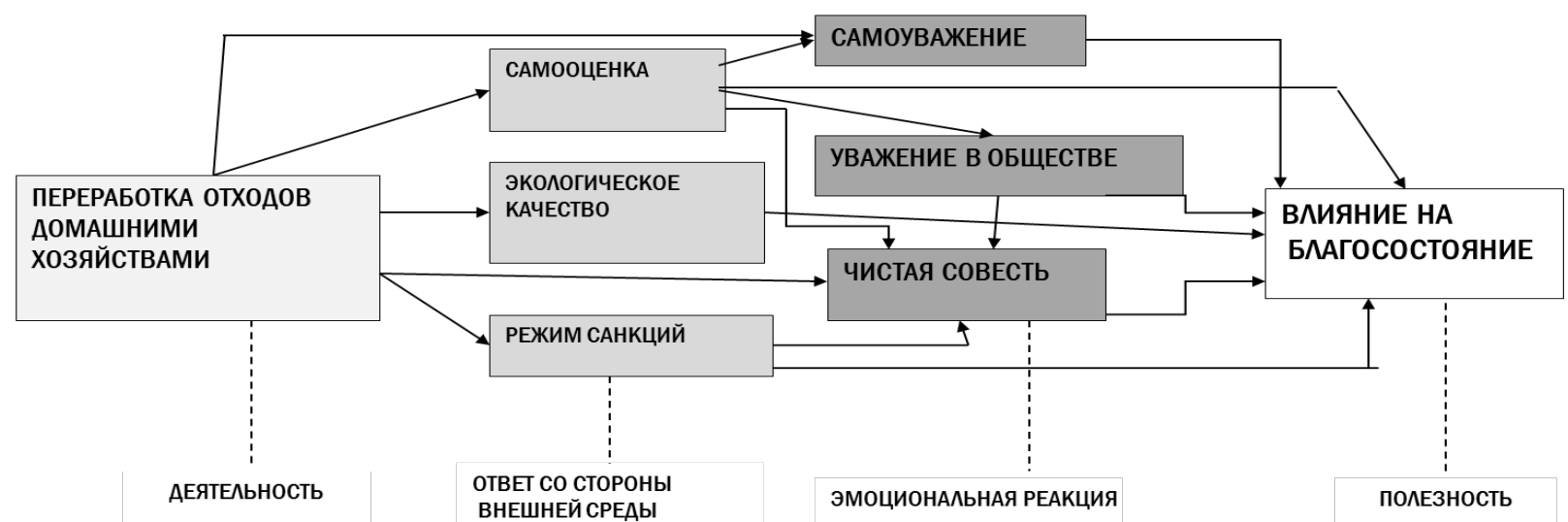

Рuc. 1. Основное влияние на полезность переработки бытовых отходов

ся, влияет на наши эмоции (третий контур) как непосредственно, так и косвенно, через эмоциональную реакцию, которую мы получаем и влияние наших действий на среду (второй контур). Все эти эффекты влияют на пользу, которую мы получаем от деятельности утилизации отходов (четвертый контур).

Полезность предполагает увеличение меры уважения в обществе и самоуважения, удовольствие, которое мы получаем от добрых дел и содействие этому. Предполагается также, что домохозяйству грозят санкции, в основном, в виде социальных санкций со стороны местного сообщества или со стороны ЖКХ, а также возникающее чувство вины, если домашнее хозяйство не участвует в процессе сбора и утилизации мусора, тем самым уменьшая всеобщую пользу.

Существование определенных норм в вопросе переработки отходов повлияют на эмоциональные реакции и наши действия. Если нормы сильные, то жителям нужно больше участвовать в процессе, для того чтобы получить определенный уровень уважения и самооценки. Кроме того, санкции и чувство вины также являются очень мощным стимулом, когда сильны и действенны нормы. Введение политических стимулов может повлиять на стоимость переработки (как стоимость и альтернативные затраты времени), а также норма для переработки в обществе. Введение новой политики может либо усилить существующее нормоповедение населения или сократить его (если домохозяйства считают, что теперь приемлема покупка услуги по утилизации вместо переработки самими) [3].

При принятии решения об утилизации от- ходов предполагается, что домохозяйство оценивает все эти последствия, максимизирует их полезность для заданного бюджета времени и денег.

Далее представлен анализ данных, собранных на основе веб-панели по вопросам из пяти различных областей: поведение домашних хозяйств: образование и переработка отходов, транспорт, выборы, энергосберегающие измерения, органическое потребление еды и польза воды. Дополнительная информация о социально-демографическом фоне, отношении к проблемам экологии, быта, характеристики и предпочтения в отношении гипотетических изменений в экологической политике.

В опросе участвовали респонденты из 10 стран-участниц: Австралии, Италии, Канады, Кореи, Мексики, Франции, Чешской Республики, Норвегия, Нидерландов и Швеции“. Обследование включало несколько вопросов, связанных с усилиями по утилизации отходов домашних хозяйств и услугами по сбору и переработке отходов домашнего хозяйства.

Большинство механизмов, рассмотренных на рисунке 1 , не могут наблюдаться непосредственно. Однако, несколько вопросов в анкете могут быть использованы в качестве показателей различий в социальной и моральной приверженности процессу рециркуляции и в ожиданиях относительно экологических последствий рециркуляционной деятельности. Например, респонденты, которые согласны с тем, что каждый человек может внести свой вклад в окружающую среду и кто участвует в рециркуляции, потому что они верят, что это полезно

*www.oecd.org/env/cpe/consumption 
окружающей среде. Они имеют более высокие ожидания относительно ценности своих усилий больше, чем другие. В свою очередь, это, вероятно, приведет к большим моральным обязательствам вносить вклад, чем от тех респондентов, которые не разделяют эти ожидания.

Респондентам, которых волнуют моральные аспекты, необходимо больше участвовать и перерабатывать, чтобы получить тот же уровень самоуважения и чистоты совести, по сравнению с респондентами, которые не разделяют эти взгляды. Таким образом, мы ожидаем, что эти переменные увеличат усилия по переработке бытовых отходов.

Моральный аспект проблемы не особо важен для тех, кто считает, что экологические проблемы будут решаться техническим прогрессом или считают, что это ответственность будущих поколений. Респондентов, которые считают, что экологическая политика не должна приводить к увеличению денежных затрат можно разделить на две группы:

- с низкой моральной ответственностью, согласными на то, что пока это не будет стоить им ничего;

- с высокими моральными обязательствами, возражающими против этого и считающими, что «мы не можем купить себе выход из этого кризиса, мы должны действовать».

Некоторые из вопросов могут также использоваться для определения взаимосвязи между мерами государственной политики и нормами на утилизацию. Например, восприятие рециркуляции как обязательной меры может повлиять на нормы несколькими способами: путем укрепления существующих норм, введения новых норм или вытеснения существующих норм.

Если государственное законодательство ужесточает нормы, оно усилит социальные санкции и чувство вины, если ответчик не выполняет их, не увеличивая усилия по утилизации. Если норма нарушена, то она уменьшит усилия по утилизации. Можно ожидать, что общая переработка отходов увеличится в сообществе, если совместные усилия обеспечиваются законодательством и это приводит к повышению качества окружающей среды.

Еще одним важным вопросом, обсуждаемом в литературе, является введение дифференцированного сбора мусора. Аргумент заключается в том, что если муниципалитет предлагает дифференцированную плату, то это сигнал, тому, что проще оплатить услугу вместо того, чтобы участвовать в рециркуляции. Это может привести к ослаблению моральных и социальных норм, а также снизит чувство вины, общности и самоуважения других моральных чувств, связанных с переработкой отходов.

Такое ослабление норм, в свою очередь, приведет к сокращению усилий по рециркуляции домашних хозяйств. Если это так, то можно ожидать, что усилия по переработке бытовых отходов будут ниже для тех, кто занят дифференцированными сборами мусора, по сравнению с теми, кто перерабатывает его, чтобы сэкономить или получить деньги.

Согласие с тем, что переработка отходов является гражданским долгом, свидетельствует о желании получить уважение, выполнить свои обязанности, для домохозяйств, которые перерабатывают отходы. Все это указывает на желание повысить уважение, которое они получают в обществе. В представленной модели оба этих эффекта могут увеличить полезность и ощущение выполненного долга перед обществом, что также положительно влияет на оценку полезности деятельности по утилизации.

Также важное значение для решения домохозяйства об утилизации имеет альтернативная стоимость времени, затрачиваемого на переработку. Можно сказать, что готовность платить (WTP) за утилизацию может быть использована как мера затрат времени отдельных домохозяйств, используемого для переработки.

Всеобщие затраты на полную рециркуляцию измеряются в денежном выражении, что равно альтернативным затратам времени на переработку [4].

WTP может быть положительным или отрицательный, в зависимости от предпочтений домохозяйства. Если обработка имеет чистый положительный эффект полезности, WTP для действия по рециркуляции домохозяйств будет отрицательными. С другой стороны, если эффект чистой полезности отрицательный - то есть, домохозяйству лучше, если фирма ЖКХ делает всю переработку, то -WTP положительный [5].

Анализ международного сравнения поведения по переработке бытовых отходов и основных переменных, описывающих различия в стимулах (цены, предложение услуг по переработке) и мотивации для утилизация (нормы и установки) представлен на диаграммах ниже. На рисунке 2 представлена средняя величина 


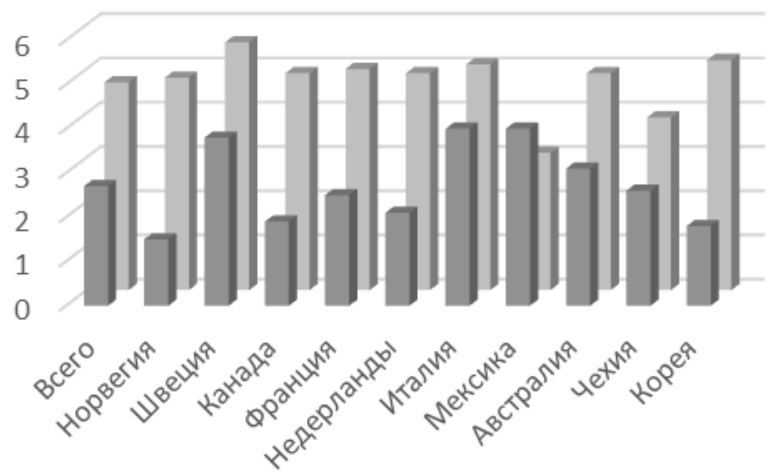

\author{
п Количество смешанных \\ отходов \\ - Количество (материалов) \\ переработанных бытовых \\ отходов
}

\title{
Puc. 2. Среднее образование и переработка бытовых отходов по странам
}

образования бытовых отходов и обработка их по странам. Образование отходов регистрируется как количество мешков со смешанными отходами для сбора домохозяйствами за каждую неделю, а действия по переработке измеряются количеством видов материалов (переработанных отходов домохозяйств), максимальное количество которых может достигать восьми.

Мы видим, что существуют относительно большие различия в среднем количестве мешков со смешанными отходами по домохозяйствам в разных странах. Корея, Норвегия, Канада, Нидерланды и Франция страны с наименьшим количеством смешанных отходов, тогда как мексиканские, итальянские и шведские домашние хозяйства производят наибольшее количество смешанных отходов. Количество рециркулированных материалов может быть причиной для относительно высокого уровня образования смешанных отходов в Мексике. Однако это не объясняет цифры для Швеции и Италии, где средства переработки относительно высоки по сравнению с образованием смешанных отходов. Одним из объяснений может быть то, что, хотя среднее количество рециркулированных материалов высокое в этих странах, интенсивность рециркуляции может повлиять на изменение выхода смешанных отходов. Другое, более разумное объяснение заключается в том, что размер мешков для смешанных отходов в разных странах разный. Например, стандартный норвежский мешок для мусора, собранного на обочине, может содержать 180 литров (ящики в Осло даже содержат 240 литров), тогда как стандартный французский мешок содержит около 80 литров.

Таким образом, далее в анализе мы сосре- доточимся на поведении домашних хозяйств по рециркуляции отходов. Глядя на количество материалов переработки домашними хозяйствами, мы видим, что шведы перерабатывают больше материалов в среднем, в то время как самое низкое среднее значение было зарегистрировано для мексиканских домохозяйств. Разница в этих двух странах больше чем 2 раза, что составляет больше чем $73 \%$ процентов.

Может быть несколько причин образования больших различий в цифрах по переработке в разных странах. Во-первых, различаются программы утилизации в разных странах. В опросе респонденты указали - к каким услугам они имеют доступ: «сбор от квартиры», «пункты выдачи или контейнеры», «возврат с возвратом» или «возврат без возврата». На рисунке 3 мы видим разнообразие видов организации утилизации отходов.

Например, в большинстве стран большое количество переработанных материалов собирается в пунктах сбора или контейнеры. Исключение составляют Корея и Канада, причем самая высокая доля услуг по сбору вторичного сырья «от квартиры». В Мексике доля переработанных материалов без каких-либо услуг по сбору самая высокая. Мы также видим высокую долю услуги «возврат с возвратом» в Норвегии, где схемы хранения бутылок используются всесторонне, а также и в Швеции, и Нидерландах. Уровень доступных услуг по переработке может быть одной из причин низких норм утилизации в Мексике и высоких - в Швеции. Тем не менее, канадцы и австралийцы перерабатывают относительно мало по сравнению с большим количеством поквартирного сбора материалов (отходов) и, вероятно, поэтому там самые низкие затраты 


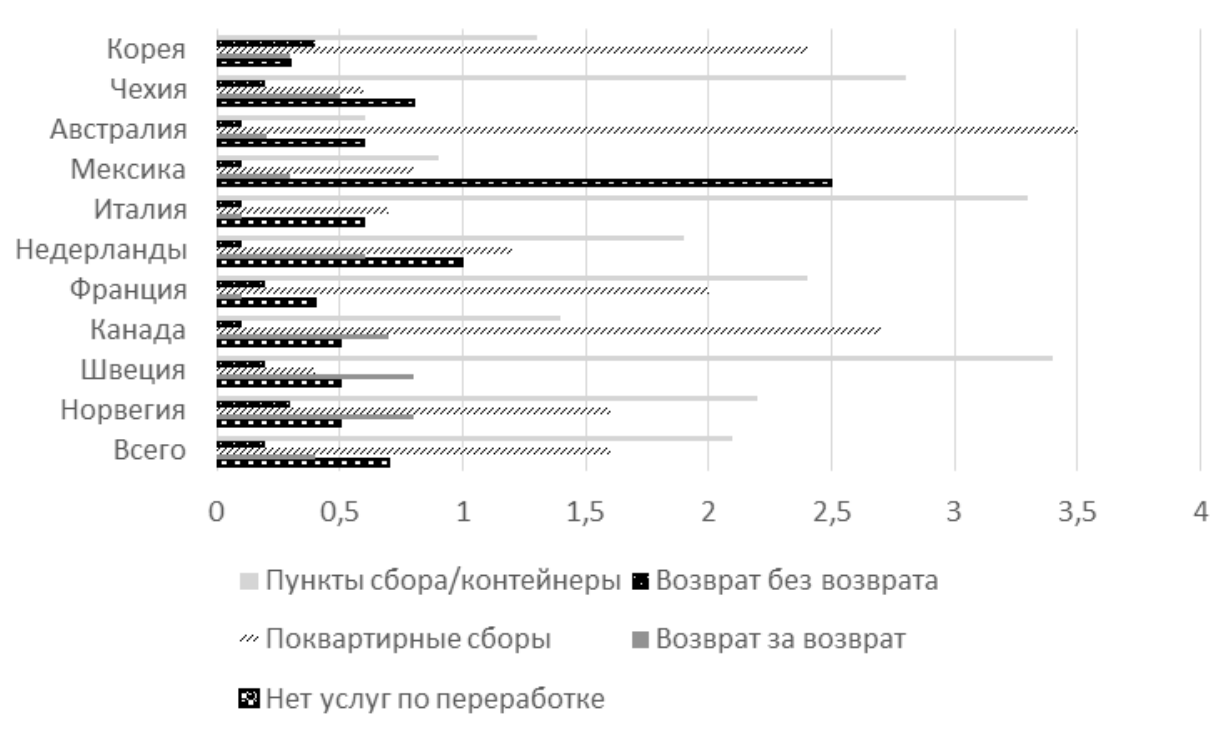

Puc. 3. Среднее количество переработанных материалов с различными видами сбора по странам

времени на переработку. Относительно низкая утилизация в Чехии (см. рисунок 2) также отличается от относительно хорошей программы переработки. Таким образом, различия в программах утилизации не являются единственным определяющим фактором сбора и переработки бытовых отходов.

На рисунке 4 показана информация о фиксированном вознаграждении (системах оплаты) за сбор мусора. Существуют разные способы: оплата за объем, за вес, за частоту вывоз отходов и т.д.
В большинстве стран используется фиксированная оплата. Исключение составляют Италия и Чехия, где значительная доля домохозяйств платит сборы в зависимости от размера домохозяйства, и Корея, где преобладающим сбором является оплата на основании объема отходов. Сбор за частоту вывоза мусора используется, в основном, в Швеции, в то время как в Мексике многие домашние хозяйства сообщают об отсутствии платы. Сборы на основе веса существуют в большинстве стран, но их доля очень мала.

В дополнение к стимулам, заложенным в

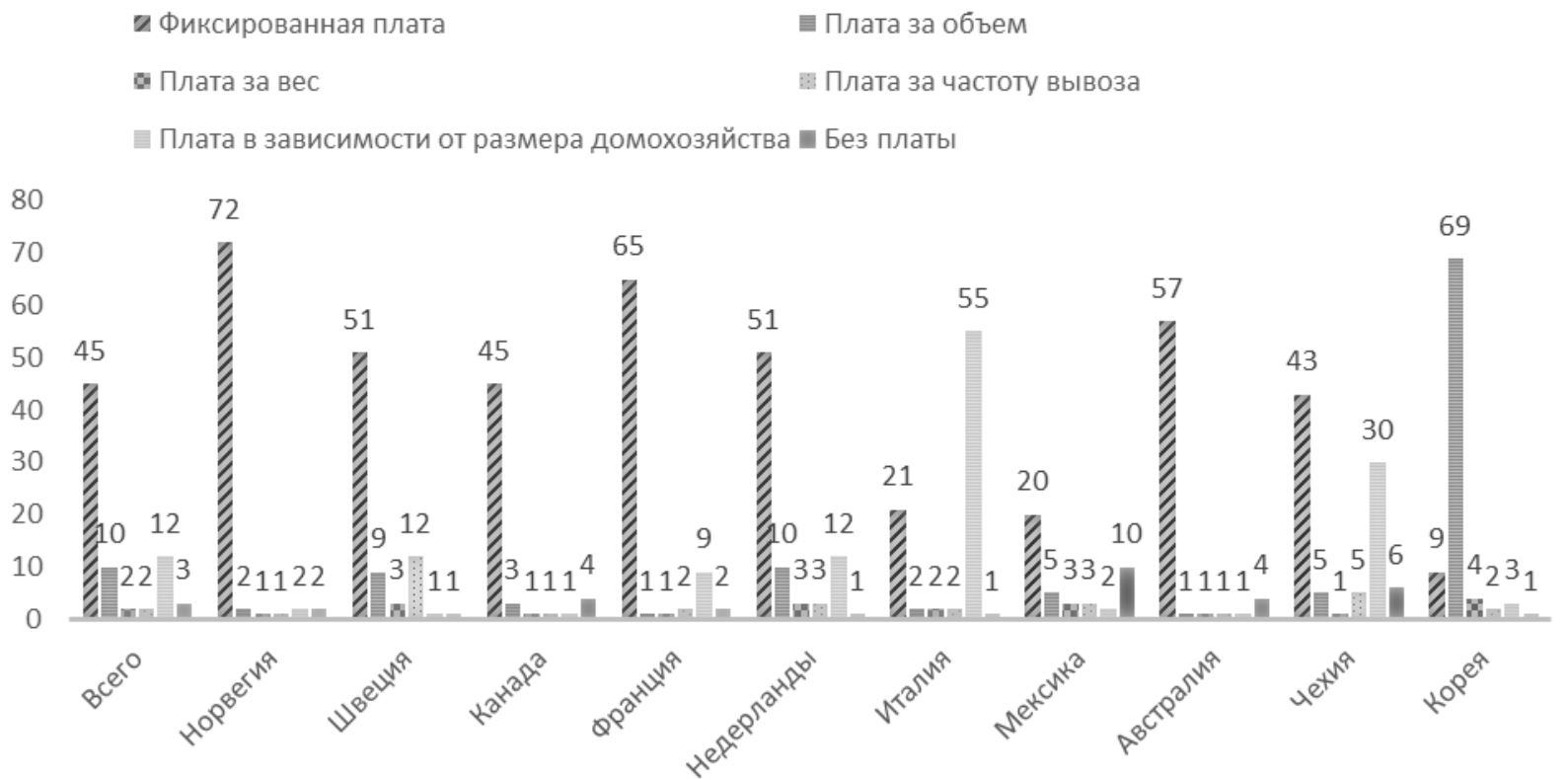

Puc. 4. Системы оплаты сбора мусора по странам 
программы утилизации, существует несколько других факторов, влияющих на утилизацию в домашних хозяйствах основанных на нормах и возможностях переработки каждого отдельного домашнего хозяйства.

Рисунок 5 иллюстрирует средний балл по мотивам рециркуляции в домохозяйствах: от 1 до 4 баллов, где 1 «совсем не важно», а 4 «очень важно». Мотивации для переработки отходов следующие:

- самым высоким средним показателем во всех странах является желание внести свой вклад в улучшение окружающей среды;

- следующее - это моральное обязательство перерабатывать отходы, потому что это рассматривается как гражданский долг.

Для остальных типов мотивации нет систематической тенденции между странами. Тем не менее, некоторые результаты, такие как низкий средний балл по респондентам, считающим рециркуляцию обязательной в Мексике и Чехии, свидетельствуют о том, что существует социальное давление для увеличения утилизации в этих странах.

Факторы, влияющие на переработку бытовых отходов: нормы, альтернативные затраты времени, программа утилизации, характеристики домохозяйств и культурные различия в разных странах, тесно взаимодействуют между собой. Это взаимодействие можно выразить следующим уравнением (1): где $\mathrm{R}_{\mathrm{h}}$ - рециркуляция по домохозяйствам, измеряемая количеством перерабатываемых материалов,

$\mathrm{HC}_{\mathrm{kh}}$ - линейная функция различных характеристик домохозяйства;

$\mathrm{WTP}_{\mathrm{h}}$ - альтернативная стоимость использованного времени на утилизацию, час;

$\mathrm{N}_{\mathrm{nh}}$ - переменные, обозначающие нормы и отношения;

$\mathrm{RS}_{\mathrm{rh}}-$ спрос на услуги утилизации;

$\mathrm{P}_{\mathrm{ph}}$ - цена услуг;

Нужно учитывать разнородность между странами в отношении того, как эти факторы влияют на переработку отходов домашних хозяйств.

Таким образом, среднее влияние нормы n на переработку домохозяйства h в стране $\mathrm{j}$ определяется как:

$$
\frac{\partial R_{h}}{\partial N_{n}}=\delta_{n}\left(1+\delta_{j}\right)
$$

Различия в процессе рециркуляции по домохозяйствам между странами, не охваченными этими переменными, учитываются константой для конкретной страны $\left(\alpha_{j}\right)$, а разброс в распределении бытовых отходов не объясненный этой функцией является погрешностью $\left(\mathrm{u}_{\mathrm{h}}\right)$, которая может различаться в разных странах.

Расчетные коэффициенты дадут полное/общее или частичное влияние на процесс рецирку-

$$
\begin{aligned}
R_{h}=\alpha_{0} & +\sum_{j} \alpha_{j} C_{j h}+\sum_{k} \beta_{k} H C_{k h}+\sum_{n} \delta_{n} N_{n h}\left(1+\sum_{j} \tilde{\delta}_{j} C_{j h}\right)+\sum_{r} \rho_{r} R S_{r h}\left(1+\sum_{j} \tilde{\rho}_{j} C_{j h}\right) \\
& +\sum_{p} \kappa_{p} P_{p h}\left(1+\sum_{j} \tilde{\kappa}_{j} C_{j h}\right)+\varphi W T P_{h}+u_{h} .
\end{aligned}
$$

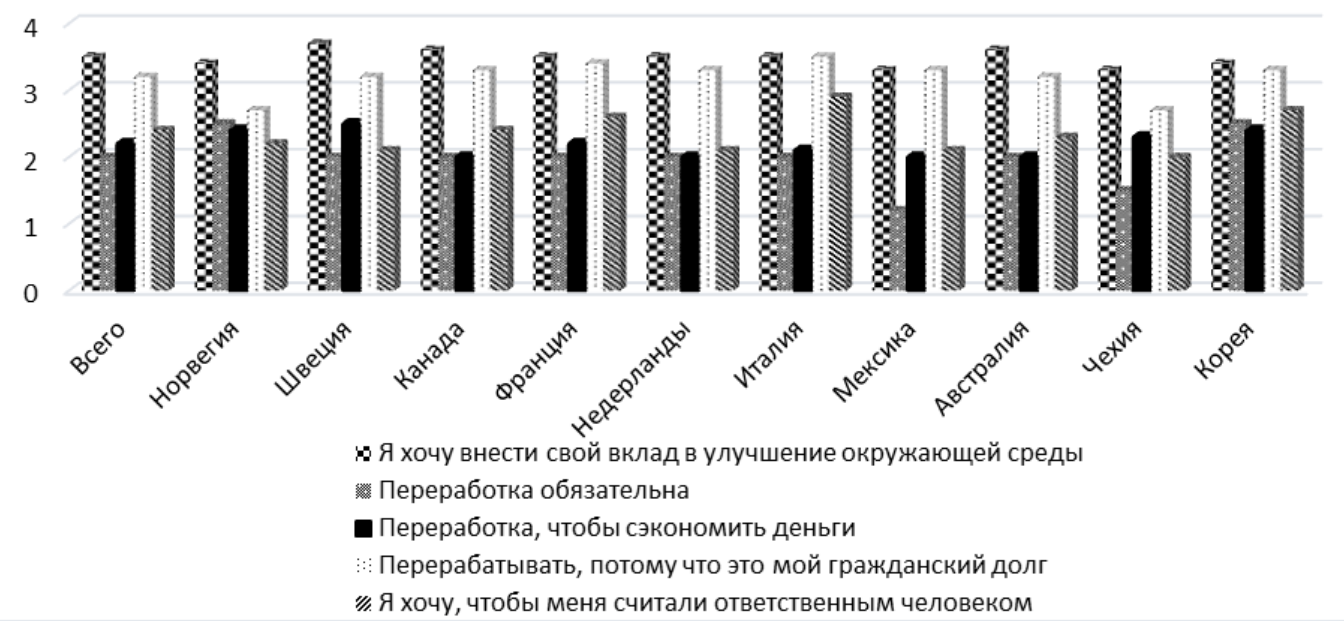

Puc. 5. Причины переработки мусора (мотивы) по странам 
ляции при введении в расчет переменного фактора при прочих равных условиях. Например, введение денежных стимулов в виде дифференцированной оплаты за мусор, предназначенной для поощрения утилизации, может вытеснить морально мотивированное поведение. Знак коэффициента показывает, является ли эффект вытеснения или цена самым сильный стимулом. Оценочные коэффициенты измеряют факторные эффекты (часто упоминаемые как при прочих равных условиях) что означает, если коэффициенты измеряют общий эффект переменных при сравнении двух равных домохозяйства.

В табл. представлены результаты оценки уравнения 1.
Часть А таблицы представляет влияние характеристик домохозяйства на переработку их отходов. Часть В представляет влияние норм и правил. В части C представлены результаты предоставления услуг по утилизации отходов, а в части D представлены влияние ценовых стимулов. Часть Е представляет влияние альтернативных затрат времени, тогда как часть $\mathrm{F}$ представляет неоднородность этих эффектов в разных странах. В первом столбце представлен коэффициент, а последний столбец дает р-значения.

Эти результаты описывают, как изменения в базовых предпочтениях влияют на текущее поведение. Они могут быть результатом правительственной политики, направленной на

Таблица. Результаты оценки утилизации домашних хозяйств $(\mathbf{n}=\mathbf{8 8 6 8})$

\begin{tabular}{|c|c|c|}
\hline & $\begin{array}{c}\text { Коэффи- } \\
\text { циент }\end{array}$ & $\begin{array}{c}\text { p-значе- } \\
\text { ние }\end{array}$ \\
\hline Константа & $-0,2581$ & 0,0649 \\
\hline Корея $(0,1)$ & 2,7459 & 0,0000 \\
\hline Швеция $(0,1)$ & 0,6409 & 0,0104 \\
\hline \multicolumn{3}{|l|}{ А. Бытовые характеристики $\left(\beta_{k}\right)$ : } \\
\hline Доход (€1000) & 0,0041 & 0,0000 \\
\hline Семья & 0.2299 & 0,0000 \\
\hline Живущие в отдельном доме & 0.2307 & 0,0000 \\
\hline Город & $-0,1241$ & 0,0013 \\
\hline Количество лет, проживающих в основном месте жительства & 0,1207 & 0,0000 \\
\hline \multicolumn{3}{|l|}{ В. Нормы, правила, ожидания и заявления о мотивах $\left(\delta_{n}\right)$} \\
\hline Член организации $(0,1)$ & 0,2051 & 0,0000 \\
\hline Окружающая среда, проблемы должны решаться будущими поколениями $(1,2,3,4)$ & $-0,0511$ & 0,0017 \\
\hline Экологическая политика не должна стоить мне лишних денег $(1,2,3,4)$ & $-0,0272$ & 0,0776 \\
\hline Озабоченность по поводу образования отходов $(1,2,3,4)$ & 0,0547 & 0,0090 \\
\hline Обеспокоены изменением климата $(1,2,3,4)$ & $-0,0643$ & 0,0007 \\
\hline Обеспокоены загрязнением воды $(1,2,3,4)$ & 0,0458 & 0,0266 \\
\hline Обеспокоены генетически модифицированными продуктами $(1,2,3,4)$ & 0,0605 & 0,0000 \\
\hline Перерабатывать, потому что это полезно для окружающей среды $(1,2,3,4)$ & 0,6373 & 0,0000 \\
\hline Перерабатывать, потому что это установлено правительством $(1,2,3,4)$ & 0,0759 & 0,0000 \\
\hline Перерабатывать, чтобы сэкономить деньги $(1,2,3,4)$ & 0,0062 & 0,6458 \\
\hline Перерабатывать, потому что я считаю, что это мой гражданский долг $(1,2,3,4)$ & 0,1840 & 0,0000 \\
\hline \multicolumn{3}{|l|}{ С. Поставка услуг по переработке $\left(p_{r}\right)$} \\
\hline Количество переработанных материалов без обслуживания & $-0,1877$ & 0,0000 \\
\hline Смешанные отходы собираются не реже одного раза в неделю $(0,1)$ & 0,4640 & 0,0000 \\
\hline Количество переработанных материалов со сбором от квартиры & 0,3476 & 0,0000 \\
\hline Количество переработанных материалов с пунктами выдачи / контейнерами & 0,2853 & 0,0000 \\
\hline Количество материалов с «возврат с возвратом» & 0,0735 & 0,0056 \\
\hline Количество переработанных материалов с «возвратом без возврата» & 0,1070 & 0,0004 \\
\hline
\end{tabular}




\begin{tabular}{|c|c|c|}
\hline \multicolumn{3}{|l|}{ D. Ценовой механизм (kp) } \\
\hline Удельный вес на основе веса $(0,1)$ & 0,1680 & 0,0084 \\
\hline Удельный вес на основе объема $(0,1)$ & $-0,5161$ & 0,0000 \\
\hline Удельный вес частоты вывоза $(0,1)$ & $-0,2262$ & 0,0061 \\
\hline \multicolumn{3}{|l|}{ 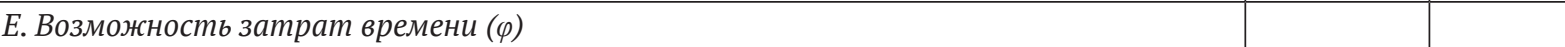 } \\
\hline WTP для того, чтобы оставить домашнюю переработку другим (€) & $-0,0150$ & 0,0000 \\
\hline \multicolumn{3}{|l|}{ F. Различия по странам (): } \\
\hline \multicolumn{3}{|l|}{ 1) Нормы, права, ожидания и личные мотивы ( $\left.p_{j}\right)$} \\
\hline Канада $(0,1)$ & 0,1179 & 0,0003 \\
\hline Нидерланды $(0,1)$ & 0,1343 & 0,0000 \\
\hline Франция $(0,1)$ & 0,2757 & 0,0000 \\
\hline Италия $(0,1)$ & 0,1780 & 0,0000 \\
\hline Швеция $(0,1)$ & 0,1986 & 0,0106 \\
\hline Австралия $(0,1)$ & 0,2088 & 0,0000 \\
\hline Корея $(0,1)$ & $-0,3943$ & 0,0000 \\
\hline \multicolumn{3}{|l|}{ 2) Механизм ценообразавания $\left(\mathrm{k}_{\mathrm{j}}\right)$} \\
\hline Недерлнды $(0,1)$ & $-1,7919$ & 0,0000 \\
\hline Мексика $(0,1)$ & $-1,6321$ & 0,0002 \\
\hline \multicolumn{3}{|l|}{ 3) Предоставление услуг по переработке( $\left.\mathrm{p}_{j}\right)$} \\
\hline Канада $(0,1)$ & $-0,4232$ & 0,0000 \\
\hline Франция $(0,1)$ & $-0,4677$ & 0,0000 \\
\hline Мексика $(0,1)$ & $-0,7414$ & 0,0000 \\
\hline Республика Чехия $(0,1)$ & $-0,3369$ & 0,0000 \\
\hline Швеция $(0,1)$ & $-0,2533$ & 0,0008 \\
\hline Австралия $(0,1)$ & $-0,6154$ & 0,0000 \\
\hline Корея $(0,1)$ & $-0,6889$ & 0,0000 \\
\hline
\end{tabular}

изменение поведения посредством информационных кампаний или обязательной утилизацией, различий в традициях и ортодоксальности среди населения, или общего общественного обсуждения экологических проблем. Зная это, можно вводить изменения в нормы и подходы к проблеме, которые станут эффективным инструментом политики в будущем.

Тем не менее, информационные кампании и программы утилизации уже широко используются в большинстве стран, и можно предположить, что с теми, кто еще не убежден, можно работать и убеждать.

Различия между странами в использовании мер политики, таких как введение денежных стимулов в форме дифференцированных сборов за мусор или увеличение предложения по утилизации, также имеют значительное влияние на переработку бытовых отходов. Увеличение предложения услуг по утилизации, как правило, имеет благоприятное влияние на переработку бытовых отходов, и способ сбора и вывоза от квартиры/дома является наиболее эффективным.

Однако, если тяжело перерабатывать отдельные отходы (для которых существуют услуги по переработке), внедрение услуг для новых отходов/материалов может снизить общую переработку. Одним из объяснений такого результата могут быть вытесняющие эффекты: введение новых услуг для отходов, которые воспринимаются как менее важные, могут снизить уверенность людей в том, что это поможет сохранить окружающую среду, которая в свою очередь может снизить моральную удовлетворенность от утилизации.

Таким образом, если государственная программа утилизации будет ориентирована на переработку наиболее важных отходов/материалов, можно избежать неблагоприятных последствий. На другом конце шкалы оценки показано, что добавление новых видов отходов для программы утилизации в странах, где население не привыкло к утилизации, нельзя достичь того 
же эффекта в сфере утилизации, что и в других странах - наиболее продвинутых в этом вопросе. Результаты исследований показывают, что это может быть потому, что альтернативные затраты времени на переработку больше, когда вводятся новые системы, Домашние хозяйства и люди должны изменить свои привычки и реорганизовать свою повседневную работу. Следует также отметить, что введение денежных стимулов может в некоторых случаях иметь противоположный эффект как, например, тот же эффект вытеснения. Но все же можно успешно ввести денежные стимулы, так как результаты показывают, что корейский эксперимент с платными сборами за вывоз мусора позволил повысить уровень утилизации бытовых отходов. Но с другой стороны, результаты также показывают, что использование ценовых стимулов в Нидерландах и Мексике было не таким успешным, поскольку наблюдаются большие вытесняющие эффекты всех денежных стимулов в этих странах.

\section{Библиографический список}

1. Fullerton, D., T.C. Kinnaman The economics of household garbage and recycling behavior. Edward Elgar, 2012. Cheltenham UK.

2. Halvorsen B. 2008. Effects of norms and opportunity cost of time on household recycling. Land Economics 84(3), 500-516.

3. Tögersen, J. 2014. Monetary incentives and environmental concern. Effects of a differentiated garbage fee. Journal of Consumer Policy 19: 125-143.

4. Frey, B.S. 2011. Not just for the money. An economic theory of personal motivation. Cheltenham, UK: Edward Elgar.

5. Bruvoll, A. 2004. Factors influencing solid waste generation and management. Journal of Solid Waste Technology and Management 27: 156-162. 